\title{
Adição de calcário no processo de compostagem da mistura de capim-elefante com torta de mamona modifica as propriedades do composto
}

Apesar de conhecida a importância de produtos alcalinos na degradação de fibras, pouco se conhece sobre os efeitos do calcário durante o processo de compostagem. Diante disso, o objetivo deste trabalho foi avaliar o efeito da adição de diferentes doses de calcário sobre o pH, condutividade elétrica (CE), densidade em base seca, emissões de $\mathrm{CO} 2$ e de NH3, teor de N, conteúdos proporcionais (\%) de massa e volume e conteúdo (\%) de $\mathrm{N}$ em relação aos valores iniciais durante a compostagem da mistura de capim-elefante (Pennisetum purpureum Schum.) e torta de mamona (Ricinus communis L.), além da avaliação dos teores de $\mathrm{Ca}, \mathrm{Mg}$, P e K ao final do período de incubação. Para tal, foi realizado um experimento em que foram adicionadas diferentes doses de calcário ( $0 ; 0,05 ; 0,5 \mathrm{e} 5 \%$, com base na massa do composto), em compostos incubados durante 90 dias. O composto foi elaborado com $67,5 \%$ de capim elefante e $32,5 \%$ de torta de mamona (massa seca). $\mathrm{O}$ pH dos compostos foi elevado pela adição de calcário, sendo este feito mais evidente aos 90 dias de incubação, onde na maior dosagem foram observados de mamona (massa seca). $\mathrm{O}$ pH dos compostos foi elevado pela adição de calcário, sendo este feito mais evidente aos 90 dias de incubação, onde na maior dosagem foram observados
maiores valores de $\mathrm{pH}$. Não foram observadas diferenças nos teores e nas perdas proporcionais de nitrogênio, da massa e do volume inicial dos compostos avaliados ao final do período de maiores valores de pH. Não foram observadas diferenças nos teores e nas perdas proporcionais de nitrogênio, da massa e do volume inicial dos compostos avaliados ao final do período de
incubação. Os teores de cálcio e magnésio foram superiores nos tratamentos em que houve adição de calcário ao final da compostagem, no entanto, os teores de fósforo e potássio não demonstraram diferenças entre os tratamentos. A adição de calcário no processo de compostagem da mistura utilizada desencadeou alterações nas propriedades do composto, sendo os efeitos expressos em maior intensidade pelo tratamento com a maior dose de calcário.

Palavras-chave: Composto orgânico; Matéria orgânica; Substâncias alcalinas.

\section{Lime addition in the composting process of mixing elephant grass with castor cake modifies the properties of the compost}

Although the importance of alkaline products in fiber degradation is known, little is known about the effects of limestone during the composting process. Therefore, the objective of this work was to evaluate the effect of adding different doses of limestone on $\mathrm{pH}$, electrical conductivity (EC), density on a dry basis, $\mathrm{CO} 2$ and $\mathrm{NH} 3$ emissions, $\mathrm{N}$ content, proportional content, mas and volume and $\mathrm{N}$ content in relation to the initial values during the composting of the mixture of elephant grass (Pennisetum purpureum Schum.) and castor bean cake (Ricinus communis L) in addition to the evaluation of $\mathrm{Ca}, \mathrm{Mg} \mathrm{P}$ and $\mathrm{K}$ contents at the end of incubation period. To this end, an experiment was carried out in which different doses of lime ( 0 ; $0.05 \%$; 0.5 and $5 \%$, observed in the proportions and proportional losses of nitrogen, mass and initial volume of the compounds evaluated at the end of the incubation period. The levels of calcium and magnesium were higher in treatments where limestone was added at the end of composting, however, the levels of phosphorus and potassium did not show differences between treatments. The addition of lime in the composting process of the mixture used triggered changes in the properties of the compost, the effects being expressed in greater intensity by treatment with the highest dose of lime.

Keywords: Organic compound; Organic matter; Alkaline substances.

Topic: Ciências do Solo

Reviewed anonymously in the process of blind peer.

Aldeane Sousa Brandão (iD

Universidade Federal Rural do Rio de Janeiro, Brasil http://lattes.cnpq.br/9204268817361135

http://orcid.org/0000-0002-6969-0551

aldeaneufrrj@yahoo.com.br

Rafael Gomes da Mota Gonçalves (iD)

Universidade Federal Rural do Rio de Janeiro, Brasil

http://lattes.cnpq.br/0244672026134100

http://orcid.org/0000-0001-9541-6698

rafaelmotag@gmail.com

Tadeu Augusto van Tol de Castro

Universidade Federal Rural do Rio de Janeiro, Brasil

http://lattes.cnpq.br/6353947754324048

http://orcid.org/0000-0003-4095-3976

tadeuvantol@hotmail.com
Received: 02/12/2020

Approved: 22/12/2020

\author{
Dione Galvão da Silva (iD \\ Embrapa Agrobiologia, Brasil \\ http://lattes.cnpq.br/1305126951006225 \\ http://orcid.org/0000-0002-2310-1854 \\ dione.galvao@embrapa.br \\ Ricardo Luís Louro Berbara (iD \\ Universidade Federal Rural do Rio de Janeiro, Brasil \\ http://lattes.cnpq.br/8529910145308595 \\ http://orcid.org/0000-0002-3649-9443 \\ rberbara@gmail.com \\ Marco Antônio de Almeida Leal \\ Embrapa Agrobiologia, Brasil \\ http://lattes.cnpq.br/6687333214208685 \\ http://orcid.org/0000-0003-3988-2277 \\ marco.leal@embrapa.br
}

Referencing this:

BRANDÃO, A. S.; GONÇALVES, R. G. M.; CASTRO, T. A. V. T.; SILVA, D. G.; BERBARA, R. L. L.; LEAL, M. A. A.. Adição de calcário no processo de compostagem da mistura de capim-elefante com torta de mamona modifica as propriedades do composto. Revista Ibero Americana de Ciências Ambientais, v.11, n.7, p.38-47, 2020. DOI:

http://doi.org/10.6008/CBPC2179-6858.2020.007.0004 


\section{INTRODUÇÃO}

A compostagem é uma alternativa tecnológica que permite a produção de insumos agrícolas, como adubos orgânicos e substratos, através da utilização de resíduos provenientes de atividades industriais e agropecuárias. De acordo com Magalhães et al. (2006), a compostagem é um bioprocesso aeróbio pelo qual ocorre a humificação do material orgânico, gerando um composto estável como produto final, capaz de melhorar as propriedades físicas, químicas e biológicas do solo.

Na produção do composto orgânico, a viabilidade econômica está diretamente relacionada com a utilização de matérias-primas disponíveis em grande quantidade e de baixo custo (LEAL, 2006). O processo necessita da mistura de materiais com baixo teor de nitrogênio $(\mathrm{N})$, associados a materiais com elevado teor de N (LEAL, 2006; LIMA, 2014). Neste sentido, tem-se o capim-elefante (Pennisetum purpureum Schum.), uma planta forrageira com baixos teores de $\mathrm{N}$ em sua composição e grande potencial de produção de matéria seca (PEREIRA et al., 2000), além da maioria das espécies serem adaptadas às condições edafoclimáticas do Brasil. Já a torta de mamona (Ricinus communis L.) é um subproduto da extração do óleo de mamona, com elevado teor de proteínas, rico em $\mathrm{N}$ e podendo ser utilizado na compostagem (AZEVEDO et al., 2001; LIMA, 2014).

Dependendo da matéria-prima utilizada, fatores intrínsecos influenciam o bom desempenho da compostagem (KIEHL, 1985). De acordo com Huang et al. (2008), a composição da fibra do material (lignina, celulose e hemicelulose) afeta de forma significativa a velocidade de degradação. Uma maneira de estimular a decomposição do material orgânico é favorecendo a hidrólise química da fibra com a utilização de agentes alcalinos, como o calcário por exemplo.

Embora seja conhecida a importância de produtos alcalinos na degradação de fibras, pouco se conhece sobre os efeitos do calcário durante o processo de compostagem. Alguns estudos têm mostrado resultados divergentes quanto a eficiência e as doses a serem aplicadas. Além disso, outro fator importante relacionado a compostagem de certos resíduos orgânicos é a liberação de $\mathrm{N}$ para a atmosfera, na forma de $\mathrm{NH}_{3}$ (PROCHNOW et al., 2001). De acordo com Kiehl (1985), a adição de substâncias alcalinas, como o calcário ou as cinzas, podem favorecer as perdas por volatilização da amônia.

Devido à escassez de resultados que descrevam os efeitos da adição de calcário sobre o processo de compostagem, torna-se pertinente a realização de experimentos científicos a fim de observar este comportamento. Sendo assim, este trabalho teve como objetivo avaliar o efeito da adição de diferentes doses de calcário sobre o $\mathrm{pH}$, condutividade elétrica (CE), densidade em base seca, emissões de $\mathrm{CO}_{2}$ e de $\mathrm{NH}_{3}$, conteúdos proporcionais (\%) de massa e volume, teor de $\mathrm{N}$, e conteúdo (\%) de $\mathrm{N}$ em relação aos valores iniciais durante a compostagem da mistura de capim-elefante (Pennisetum purpureum Schum.) e torta de mamona (Ricinus communis L.), além da avaliação dos teores de outros macronutrientes ao final dos 90 dias de incubação. 


\section{MATERIAIS E MÉTODOS}

\section{Caracterização Experimental}

O experimento foi conduzido na Fazendinha Agroecológica do $\mathrm{Km} \mathrm{47,} \mathrm{localizada} \mathrm{no} \mathrm{município} \mathrm{de}$ Seropédica - RJ, em casa de vegetação no setor de produção de mudas do Sistema Integrado de Produção Agroecológica, situada na latitude $22^{\circ} 45^{\prime} \mathrm{S}$, longitude $43 \circ 41^{\prime} \mathrm{W}$ e 33 metros de altitude. O clima da região pertence à classe Aw segundo a classificação de Köppen.

A compostagem foi realizada em caixas de 100 litros, mantidas em local seco e arejado durante 90 dias de incubação. O composto foi elaborado com 67,5\% de capim elefante (CEL) (Penissetum purpureum Schum), fragmentado em pedaços de 3,0 cm com auxílio de uma picadeira mecânica, e 32,5\% de torta de mamona (TM) (Ricinus communis L.), sendo avaliadas as caraterísticas nutricionais do capim elefante e da torta de mamona utilizados na compostagem (Tabela 1). Após 3 dias do início da incubação, foi adicionado calcário dolomítico com as seguintes características químicas: soma dos óxidos =48,0\%; $\mathrm{CaO}=36,0 \% ; \mathrm{MgO}$ $=12,0 \%$; poder de neutralização = 94,20\%; PRNT = 85,0\%; e as seguinte granulometrias: peneira 2,00 $\mathrm{mm}=$ $100,0 \%$; peneira $0,84 \mathrm{~mm}=96,0 \%$; e peneira $0,30 \mathrm{~mm}=80,0 \%$.

Os compostos foram elaborados utilizando-se as seguintes proporções: • composto sem calcário. • composto + calcário equivalente a $0,05 \%$ da massa seca do composto. • composto + calcário equivalente a 0,5\% da massa seca do composto. • composto + calcário equivalente a 5,0\% da massa seca do composto.

Tabela 1: Teores de N, Ca, Mg, P e K do capim elefante e da torta de mamona utilizados na compostagem.

\begin{tabular}{llllll}
\hline & $\mathrm{N}$ & $\mathrm{Ca}$ & $\mathrm{Mg}$ & $\mathrm{P}$ & $\mathrm{K}$ \\
& $-\mathrm{-}$ & $\mathrm{-}$ & & \\
\hline Capim elefante & 7,30 & 3,36 & 3,43 & 1,55 & 11,39 \\
Torta de mamona & 56,40 & 4,23 & 4,43 & 8,86 & 10,25 \\
\hline
\end{tabular}

Avaliações das Propriedades dos Compostos

A avaliação da temperatura foi realizada aos $1,4,7,14,21,30,45,60,90$ dias após o início da incubação. Aos 0 , 7, 14, 30, 45, 60, 90 dias foram realizados os revolvimentos das pilhas e obtidas as amostras para avaliação de $\mathrm{pH}$, condutividade elétrica (CE), densidade em base seca, emissões de $\mathrm{CO}_{2}$ e de $\mathrm{NH}_{3}$, teor de $\mathrm{N}$, conteúdos proporcionais (\%) de massa e volume e conteúdo (\%) de $\mathrm{N}$ em relação aos valores iniciais. No final do processo de compostagem, aos 90 dias, foram avaliados os teores de $\mathrm{Ca}, \mathrm{Mg}, \mathrm{P}$ e $\mathrm{K}$, por meio da digestão das amostras, conforme o método descrito por Silva (2009).

A medição de temperatura foi realizada em três posições na caixa, inserindo o termômetro a $20 \mathrm{~cm}$ de profundidade a partir da superfície superior. As amostragens foram realizadas com três repetições, após o composto ser minuciosamente misturado. As análises de pH e de CE foram realizadas em solução de água destilada (5:1 v/v). Os teores de $\mathrm{N}$ foram obtidos de acordo com os procedimentos descritos por Silva (2009).

As emissões de $\mathrm{CO}_{2}$ foram quantificadas conforme metodologia descrita por Oliveira et al. (2014), modificada devido alteração da temperatura de incubação para $30^{\circ} \mathrm{C}$, ao invés dos $25^{\circ} \mathrm{C}$ do método original. As emissões de $\mathrm{NH}_{3}$ foram realizadas de duas maneiras: a) por meio de incubação, conforme descrito para emissão de $\mathrm{CO}_{2}$; b) por meio de um sistema composto por câmara semiaberta livre estática, descrita e 
calibrada por Araújo et al. (2009).

O conteúdo proporcional de massa foi calculado por meio da quantidade de massa seca presente em cada caixa de composto após um determinado tempo, comparado com a quantidade de massa seca presente na mesma caixa no início da compostagem. A massa seca de cada caixa de composto foi calculada em função da sua massa úmida e do teor de matéria seca, determinado com base em três amostras/repetições para cada caixa. A variação proporcional do volume foi calculada da mesma forma. O conteúdo proporcional de $\mathrm{N}$ foi calculado considerando os valores de massa das caixas de composto e do teor deste nutriente.

\section{Delineamento Experimental e Análises Estatísticas}

O delineamento experimental foi por meio de parcela subdividida, com tratamento na parcela e tempo de compostagem na subparcela, em delineamento inteiramente casualizado contendo três repetições. A análise estatística foi realizada por meio da análise de variância, seguida de teste de médias que foram avaliados somente no final do processo de compostagem. Os valores observados no final do processo, após 90 dias de incubação, foram comparados por meio do teste de Scott-Knott.

\section{RESULTADOS E DISCUSSÃO}

Os resultados da análise de variância estão apresentados na Tabela 2, na qual os coeficientes de variações referentes as doses de calcário estão representadas na parcela principal e ao tempo de compostagem nas subparcelas. Verificou-se efeito significativo dos tratamentos com diferentes doses de calcário em relação às características de temperatura, $\mathrm{pH}$, densidade, emissão de $\mathrm{NH}_{3}$ por incubação e proporção do volume inicial. Também foi observado efeito significativo do tempo de compostagem em relação a todos os parâmetros avaliados, mostrando que houve variações significativas de todas as características ao longo do processo de compostagem. Ocorreu interação entre a aplicação de diferentes doses de calcário e o tempo de compostagem na maior parte dos parâmetros analisados, exceto teor de $\mathrm{N}$, emissão de $\mathrm{CO}_{2}$, emissão de $\mathrm{NH}_{3}$ câmara, proporção da massa inicial e proporção do $\mathrm{N}$ inicial.

Tabela 2: Resultados da análise de variância com as dosagens de calcário nas parcelas principais e o tempo de compostagem nas subparcelas.

\begin{tabular}{|c|c|c|c|c|c|}
\hline & \multicolumn{3}{|c|}{ Nível de significância } & \multicolumn{2}{|l|}{ CV\% } \\
\hline & Tratamento & Tempo & Interação & Parc. & Subparc. \\
\hline Temperatura & $0,007^{* *}$ & $<0,001 * *$ & $<0,001 * *$ & 2,56 & 1,85 \\
\hline $\mathrm{pH}$ & $<0,001 * *$ & $<0,001 * *$ & $<0,001 * *$ & 0,41 & 0,50 \\
\hline Condutividade elétrica ${ }^{1}$ & $0,260 \mathrm{~ns}$ & $<0,001 * *$ & $<0,001 * *$ & 24,18 & 13,35 \\
\hline Densidade & $<0,001 * *$ & $<0,001 * *$ & $0,002 * *$ & 4,47 & 6,66 \\
\hline Teor de $\mathrm{N}$ & $0,211 \mathrm{~ns}$ & $<0,001 * *$ & $0,320 \mathrm{~ns}$ & 5,84 & 4,35 \\
\hline Emissão de $\mathrm{CO}_{2}$ & 0,504 ns & $<0,001 * *$ & 0,080 ns & 11,24 & 11,55 \\
\hline Emissão de $\mathrm{NH}_{3}$ incubação & $0,008 * *$ & $<0,001 * *$ & $<0,001 * *$ & 17,66 & 17,73 \\
\hline Emissão de $\mathrm{NH}_{3}$ câmara & $0,542 \mathrm{~ns}$ & $<0,001 * *$ & $0,236 \mathrm{~ns}$ & 36,82 & 39,90 \\
\hline Proporção da massa inicial & $0,346 \mathrm{~ns}$ & $<0,001 * *$ & $0,162 \mathrm{~ns}$ & 3,00 & 3,04 \\
\hline Proporção do volume inicial & $0,028 *$ & $<0,001 * *$ & $0,002 * *$ & 2,81 & 2,85 \\
\hline Proporção do N inicial & $0,846 \mathrm{~ns}$ & $<0,001 * *$ & $0,506 \mathrm{~ns}$ & 8,19 & 6,00 \\
\hline
\end{tabular}

**: significativo ao nível de 1,0\%; *: significativo ao nível de 5,0\%; ns: não significativo. 1- Valores transformados para $\log (\mathrm{x})$.

Todos os tratamentos apresentaram temperatura (으) elevada no início do processo de 
compostagem em comparação a temperatura do ambiente, alcançando valores superiores a $65^{\circ} \mathrm{C}$ após 24 horas. Porém com o decorrer dos dias esses valores foram diminuindo gradativamente, até que dos 10 aos 15 dias após o início do processo houve novamente aumento da temperatura do composto em todos os tratamentos. A partir do 15으 dia de incubação, a temperatura dos compostos voltou a cair, se estabilizando próximos aos 30 dias, permanecendo assim até o final do período de incubação, com valores bem próximos à temperatura ambiente (Figura 1). Valores altos no início do processo de compostagem revelam elevada atividade microbiana, e são um indicativo de que o processo está ocorrendo de forma correta (HECK et al., 2013). As temperaturas observadas nos compostos foram similares, indicando que a adição de calcário, independe da dose, não exerceu influência sobre este parâmetro.

Em relação ao $\mathrm{pH}$, ocorreram efeitos significativos do tempo de compostagem, tratamentos e da interação tempo $\mathrm{x}$ tratamento. As maiores diferenças de $\mathrm{pH}$ dos compostos, devido à adição de calcário foram observadas aos 90 dias de incubação. $\mathrm{O}$ pH do tratamento que recebeu maior dosagem de calcário apresentou valor mais elevado $(7,1)$ em comparação aos demais tratamentos, que apresentaram valores entre 6,5 e 6,7. No entanto, é possível observar que o composto contendo a maior dose de calcário apresentou maiores valores de $\mathrm{pH}$, de maneira geral, durante todo o processo de compostagem (Figura 2). Este resultado pode ser explicado pelo fato do calcário ser um material de baixa solubilidade e de reação lenta (ALVAREZ et al., 1999), exercendo efeito de alcalinização sobre o composto.

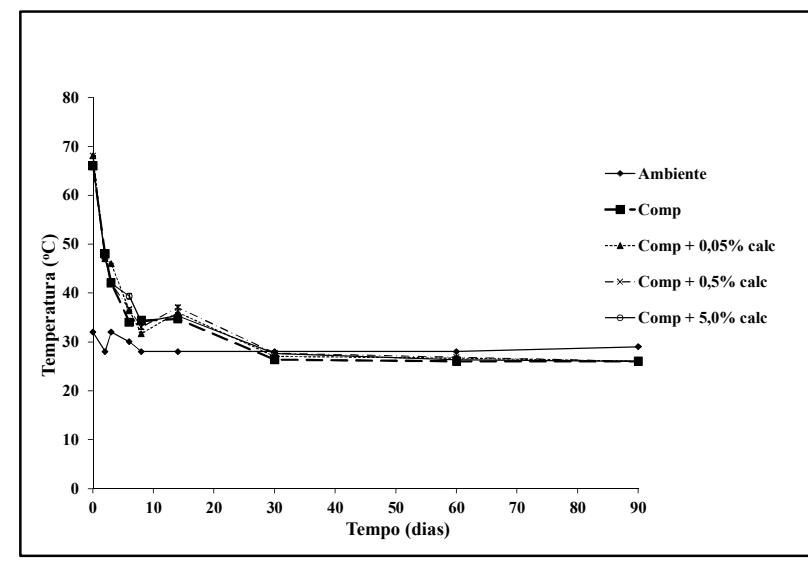

Figura 1: Temperaturas observadas durante a compostagem de capim elefante e torta de mamona com a adição de diferentes doses de calcário.

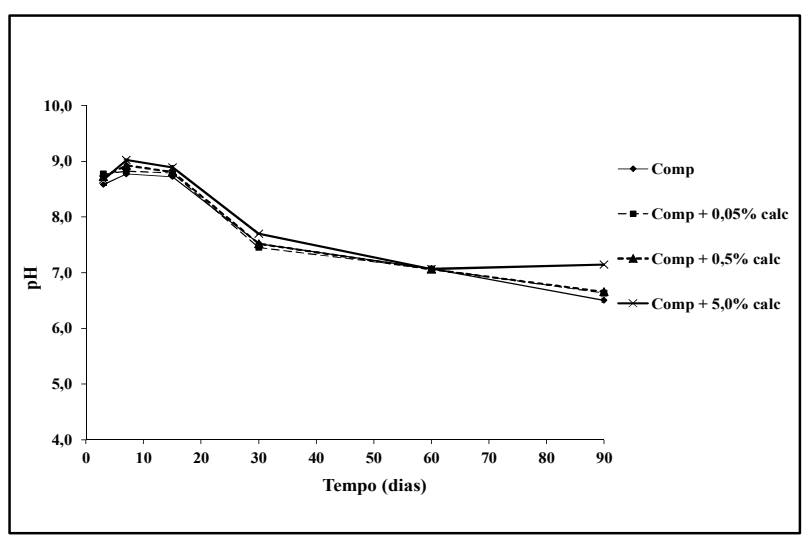

Figura 2: Valores de $\mathrm{pH}$ observados durante a compostagem de capim elefante e torta de mamona com a adição de diferentes doses de calcário.

Com o objetivo de verificar a quantidade de sais presente foi realizada a avaliação da condutividade elétrica (CE) ( $\left.\mu \mathrm{S} \mathrm{cm}^{-1}\right)$, sendo que quanto maior for esse valor maior será presença de sais no composto. $O$ composto com maior dose de calcário não apresentou maior valor de condutividade elétrica quando comparado aos demais tratamentos, sendo até mesmo observado os menores valores de CE neste tratamento ao final dos 90 dias de compostagem. Os maiores valores de CE ao final do período de incubação foram observados no composto sem adição de calcário. Porém, aos 7, 15, 30 e 60 dias, o tratamento com a maior dose de calcário adicionada ao composto apresentou os mais elevados valores de CE em relação aos demais tratamentos (Figura 3). Este diferenciado comportamento devido à adição de calcário pode ser um indício de seus efeitos e reações sobre a compostagem da mistura em questão. 
Os valores de densidade $\left(\mathrm{kg} \mathrm{m}^{3}\right.$ ) obtidos no presente estudo variaram de 100 a $160 \mathrm{~kg} \mathrm{~m}^{-3}$ (Figura 4). Segundo Kampf (2000), os valores de densidade para o sistema de mudas em bandejas multicelulares devem estar entre 100 e $300 \mathrm{~kg} \mathrm{~m}^{3}$. Esse é um parâmetro muito importante, uma vez que está associado ao manejo e ao crescimento radicular. Valores de densidade muito elevados podem causar impedimento ao crescimento do sistema radicular.

Observa-se na Figura 4, que praticamente durante todo o processo de compostagem, o tratamento com maior adição de calcário apresentou densidade superior aos demais tratamentos, o que era esperado pois a adição de calcário aumenta a massa do composto, sem aumentar o seu volume.

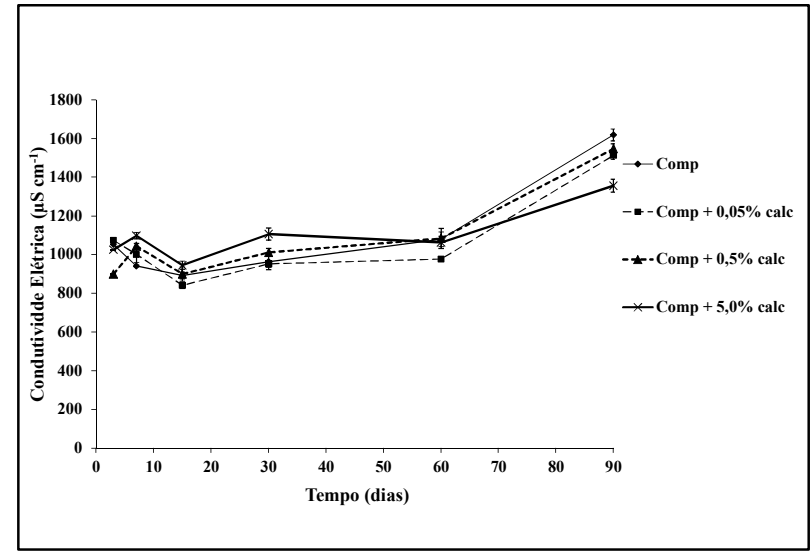

Figura 3: Valores de condutividade elétrica observados durante a compostagem de capim elefante e torta de mamona com a adição de diferentes doses de calcário.

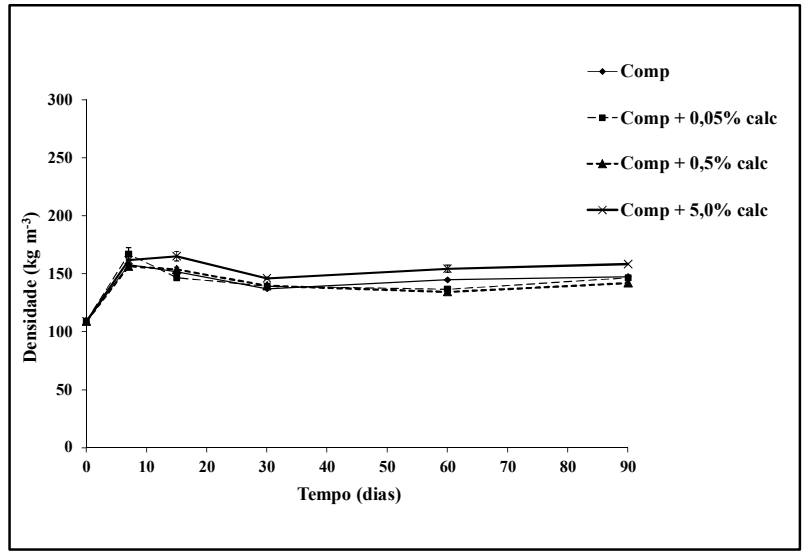

Figura 4: Valores de densidade observados durante a compostagem de capim elefante e torta de mamona com a adição de diferentes doses de calcário.

Os teores de $\mathrm{N}\left(\mathrm{mg} \mathrm{g}^{-1}\right)$ aumentaram ao longo do processo de compostagem atingindo, aos 90 dias, valores acima de $20 \mathrm{mg} \mathrm{g}^{-1}$ em todos os tratamentos. Houve comportamento diferenciado entre os tratamentos no início da compostagem, porém após 15 dias de incubação os teores de $\mathrm{N}$ passaram a apresentar respostas mais lineares (Figura 5). Conforme Leal et al. (2013), esses valores são superiores aos normalmente encontrados nos fertilizantes orgânicos tradicionais. Melo et al. (2008), observaram, ao caracterizar diversos resíduos orgânicos, teores de $\mathrm{N}$ total próximos a $11,0 \mathrm{mg} \mathrm{g}^{-1} \mathrm{em}$ esterco bovino.

Em relação à emissão de $\mathrm{CO}_{2}\left(\mathrm{mg} \mathrm{CO}_{2} \mathrm{~g}^{-1} \mathrm{MS} \mathrm{dia}^{-1}\right)$, todos os tratamentos apresentaram valores elevados no início do processo de compostagem, com redução gradual até aproximadamente 30 dias, quando a emissão de $\mathrm{CO}_{2}$ alcançou um patamar que se manteve até o final da incubação. Isto demonstra elevada atividade biológica no início do processo de compostagem, com posterior estabilização. Aos 30 dias de compostagem, foi observado que o tratamento sem adição de calcário apresentou maiores taxa de emissão de $\mathrm{CO}_{2}$, porém este mesmo composto apresentou menor emissão aos 90 dias quando comparado com os demais tratamentos, demonstrando a diferenciação comportamental devido à aplicação da substância alcalina (Figura 6). Segundo Oliveira et al. (2014), a emissão de $\mathrm{CO}_{2}$ está relacionada, principalmente, com o auto aquecimento e consumo de $\mathrm{O}_{2}$. 


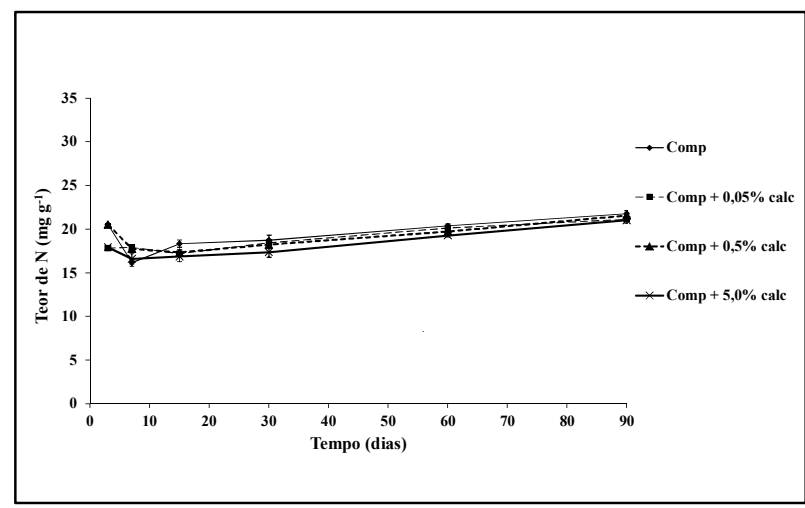

Figura 5: Teores de $\mathrm{N}$ observados durante a compostagem de capim elefante e torta de mamona com a adição de diferentes doses de calcário.

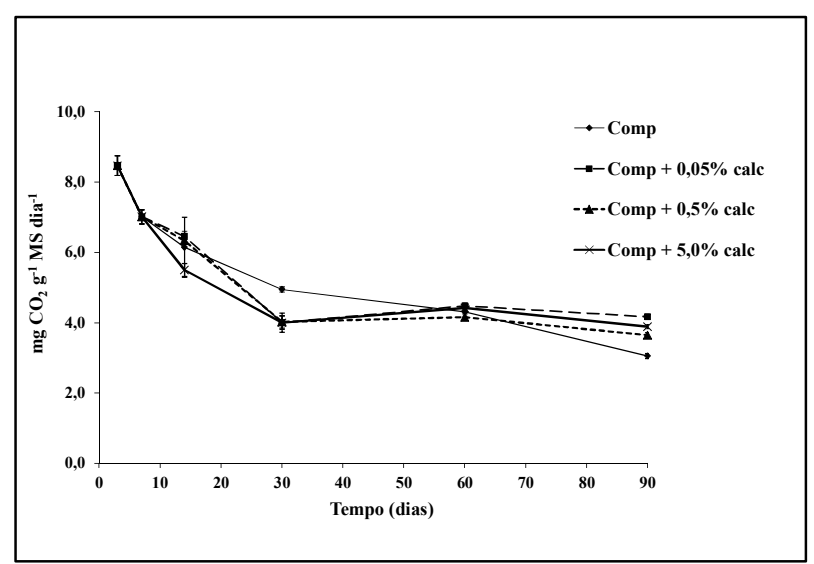

Figura 6: Emissão de $\mathrm{CO}_{2}$ avaliada por meio da incubação de amostras do composto de capim elefante e torta de mamona com a adição de diferentes doses de calcário.

Os resultados de emissão de $\mathrm{NH}_{3}\left(\mathrm{mg} \mathrm{NH}_{3} \mathrm{~g}^{-1} \mathrm{MS}\right.$ dia-1) avaliados por meio do método de incubação estão apresentados na Figura 7, onde podemos observar uma elevada emissão no início da compostagem, com posterior redução até valores próximos de zero aos 30 dias de incubação. Este comportamento é comum no processo de compostagem, devido aos elevados valores de $\mathrm{pH}$, acima de 8,0, e à maior proporção de $\mathrm{N}$ na forma de $\mathrm{NH}_{3}$ que ocorrem no início do processo. A volatilização de $\mathrm{NH}_{3}$ é maior em $\mathrm{pH}$ alcalino, porém a maior parte do $\mathrm{N}$-amônio já havia se transformado em $\mathrm{N}$-nitrato, sendo evidenciado pelas nulas taxas de emissões de $\mathrm{NH}_{3}$ a partir dos 30 dias de incubação dos compostos, independentemente do tratamento adotado

Os resultados de emissão de $\mathrm{NH}_{3}\left(\mathrm{mg} \mathrm{NH}_{3} \mathrm{~g}^{-1} \mathrm{MS}\right.$ dia$\left.^{-1}\right)$ avaliados por meio de câmaras coletoras estão apresentados na Figura 8. As respostas são parecidas com os resultados obtidos pelo método de incubação, com elevada emissão no início da compostagem, seguido por redução até valores próximos de zero aos 21 dias de incubação. No entanto, diferente do método anterior, as respostas dos tratamentos verificadas na emissão de $\mathrm{NH}_{3}$, pela avaliação por meio de câmaras coletoras, apresentaram menor linearidade nas taxas de emissão de $\mathrm{NH}_{3}$ até os 10 dias de incubação.

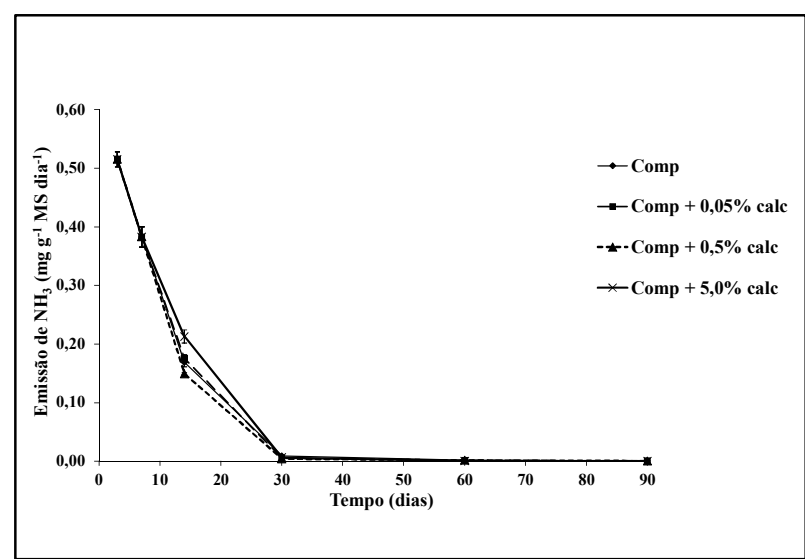

Figura 7: Emissão de $\mathrm{NH}_{3}$ avaliada por meio da incubação de amostras do composto de capim elefante e torta de mamona com a adição de diferentes doses de calcário.

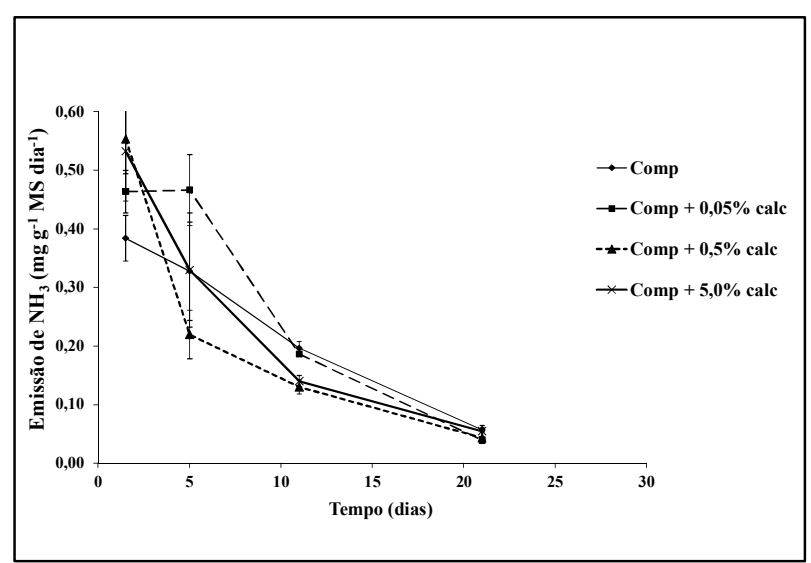

Figura 8: Emissão de $\mathrm{NH}_{3}$ avaliada por meio de câmaras coletoras instaladas nas caixas de composto de capim elefante e torta de mamona com a adição de diferentes doses de calcário. 
Os valores de proporção relativa em relação à massa inicial (\%) estão apresentados na Figura 9. Segundo Inácio et al. (2009), a perda de carbono através do $\mathrm{CO}_{2}$ e a intensa perda de vapor são responsáveis por reduções de $25-50 \%$ no volume e de $40-80 \%$ no peso total do composto. Todos os tratamentos apresentaram comportamento semelhante, com perdas de aproximadamente $40 \%$ da massa ao longo de 90 dias de compostagem.

Já os resultados de proporção relativa em relação ao volume inicial (\%) mostram que houve perdas de aproximadamente $60 \%$ do volume ao longo de 90 dias de compostagem em todos os tratamentos (Figura 10).

A Figura 11 apresenta os valores de proporção relativa em relação ao conteúdo inicial de nitrogênio (N) (\%). Foram observadas perdas de aproximadamente $40 \%$ do $\mathrm{N}$ em todos os tratamentos adotados, ao longo de 90 dias de compostagem.

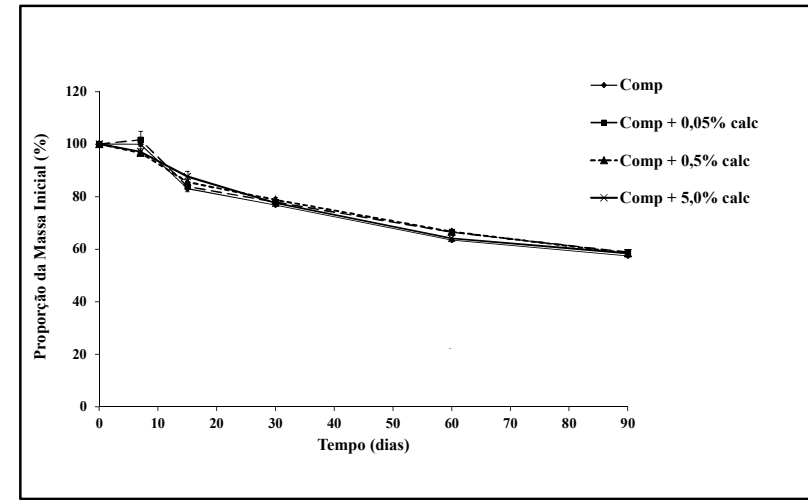

Figura 9: Proporção relativa (\%) em relação à massa inicial observada durante a compostagem de capim elefante e torta de mamona com a adição de diferentes doses de calcário.

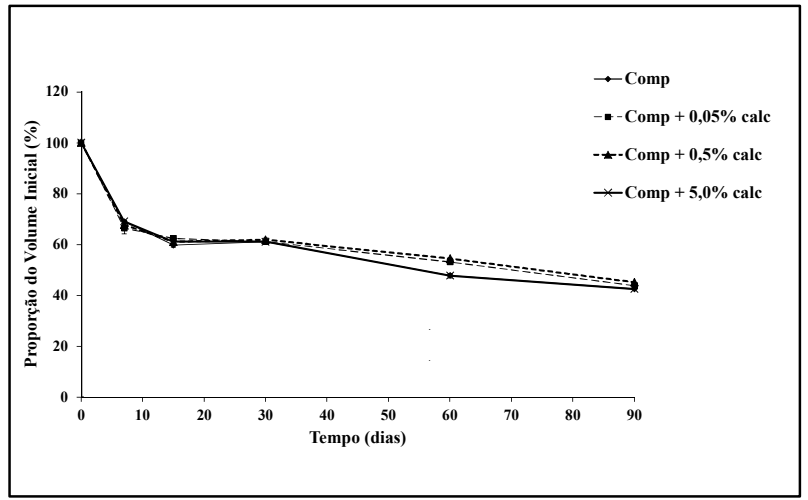

Figura 10: Proporção relativa (em \%) em relação ao volume inicial observada durante a compostagem de capim elefante e torta de mamona com a adição de diferentes doses de calcário.

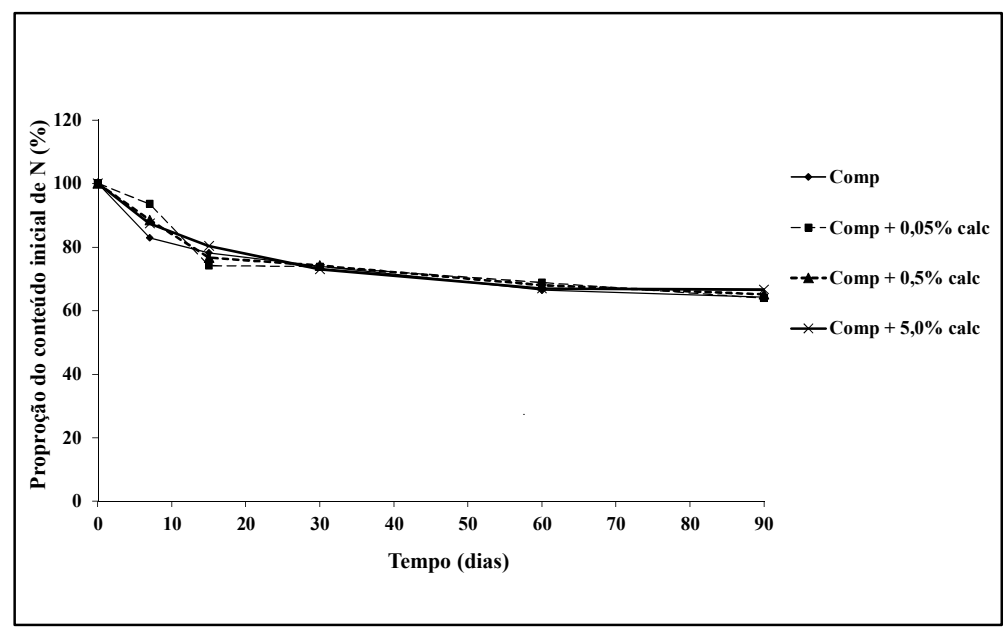

Figura 11: Proporção relativa (em \%) em relação ao conteúdo inicial de $\mathrm{N}$ observada durante a compostagem de capim elefante e torta de mamona com a adição de diferentes doses de calcário.

Na Tabela 3 estão apresentados os valores dos parâmetros avaliados em cada tratamento ao final dos 90 dias de incubação. A adição de calcário resultou em aumentos dos valores de pH do composto independentemente da dose aplicada, porém foi observada superioridade significativa no $\mathrm{pH}$ do composto em que houve adição de calcário na maior concentração. Ao final dos 90 dias de incubação, o tratamento 
com adição da maior dose de calcário apresentou valores significativamente menores de $\mathrm{CE}\left(\mu \mathrm{S} \mathrm{cm}{ }^{-1}\right)$ do que os demais tratamentos, porém também mostrou aumento significativo nos valores de densidade $\left(\mathrm{g} \mathrm{kg}^{-1}\right) \mathrm{em}$ comparação aos demais compostos. Não foram observadas diferenças significativas nos teores de N (g kg-1), na perda proporcional de $\mathrm{N}(\%)$ e nas proporções da massa (\%) e volume (\%) iniciais ao final do processo de compostagem. Os teores de cálcio $(\mathrm{Ca})\left(\mathrm{g} \mathrm{kg}^{-1}\right)$ e magnésio $(\mathrm{Mg})\left(\mathrm{g} \mathrm{kg}^{-1}\right)$ foram significativamente superiores nos tratamentos em que houve adição de calcário, por outro lado os teores de fósforo (P) $\left(\mathrm{g} \mathrm{kg}^{-1}\right)$ e potássio (K) $\left(\mathrm{g} \mathrm{kg}^{-1}\right)$ não apresentaram diferenças significativas entre os tratamentos.

Tabela 3: Características avaliadas ao final do processo de compostagem (90 dias) em caixas de composto (capim elefante + torta de mamona) misturado com diferentes doses de calcário (Calc).

\begin{tabular}{|c|c|c|c|c|c|c|c|c|}
\hline \multirow{2}{*}{$\begin{array}{l}\text { Características } \\
\mathrm{pH}\end{array}$} & \multirow{2}{*}{$\begin{array}{l}\text { Comp } \\
6,5\end{array}$} & \multicolumn{3}{|c|}{ Comp $+0,05 \%$ calc } & \multicolumn{2}{|c|}{ Comp $+0,5 \%$ calc } & \multicolumn{2}{|c|}{$\begin{array}{l}\text { Comp }+5,0 \% \\
\text { calc }\end{array}$} \\
\hline & & $\mathrm{C}$ & 6,6 & $\mathrm{~b}$ & 6,7 & $\mathrm{~b}$ & 7,1 & $\mathrm{a}$ \\
\hline Condutividade Elétrica $\left(\mu \mathrm{S} \mathrm{cm}^{-1}\right)$ & 1617 & $\mathrm{a}$ & 1511 & $\mathrm{a}$ & 1546 & $\mathrm{a}$ & 1355 & $b$ \\
\hline Densidade $\left(\mathrm{kg} \mathrm{m}^{-3}\right)$ & 147 & $\mathrm{~b}$ & 146 & $\mathrm{~b}$ & 142 & $\mathrm{~b}$ & 158 & $\mathrm{a}$ \\
\hline Teor de $\mathrm{N}\left(\mathrm{g} \mathrm{kg}^{-1}\right)$ & 21,7 & $\mathrm{a}$ & 21,1 & $\mathrm{a}$ & 21,5 & $\mathrm{a}$ & 21,0 & $\mathrm{a}$ \\
\hline Proporção da massa inicial (\%) & 57,4 & $\mathrm{a}$ & 58,8 & $\mathrm{a}$ & 58,4 & $\mathrm{a}$ & 58,5 & $\mathrm{a}$ \\
\hline Proporção do volume inicial (\%) & 42,5 & a & 43,8 & $\mathrm{a}$ & 45,1 & a & 42,5 & a \\
\hline Proporção do N inicial (\%) & 64,2 & $\mathrm{a}$ & 63,9 & $\mathrm{a}$ & 65,1 & $\mathrm{a}$ & 66,6 & a \\
\hline Teor de Ca $\left(\mathrm{g} \mathrm{kg}^{-1} \mathrm{CV}=7,56 \%\right)$ & 8,0 & $\mathrm{c}$ & 8,5 & $\mathrm{c}$ & 10,5 & $\mathrm{~b}$ & 28,4 & a \\
\hline Teor de $\mathrm{Mg}\left(\mathrm{g} \mathrm{kg}^{-1} \mathrm{CV}=4,36 \%\right.$ ) & 6,2 & $\mathrm{~b}$ & 6,4 & $b$ & 6,9 & $\mathrm{~b}$ & 10,5 & a \\
\hline Teor de $\mathrm{P}\left(\mathrm{g} \mathrm{kg}^{-1} \mathrm{CV}=4,59 \%\right)$ & 4,7 & $\mathrm{a}$ & 4,9 & a & 5,2 & a & 4,8 & a \\
\hline Teor de $\mathrm{K}\left(\mathrm{g} \mathrm{kg}^{-1} \mathrm{CV}=3,66 \%\right)$ & 17,0 & a & 17,4 & $\mathrm{a}$ & 18,4 & $\mathrm{a}$ & 17,2 & $\mathrm{a}$ \\
\hline
\end{tabular}

Médias seguidas da mesma letra não diferem entre si ao nível de 5,0\% de probabilidade pelo teste de Scott-Knott

\section{CONCLUSÕES}

A adição de calcário em compostos formulados com a mistura de capim elefante e torta de mamona, resultou em aumento do $\mathrm{pH}$ do composto, resultados que foram mais evidentes aos 90 dias de incubação.

A aplicação de calcário na maior dose resultou nos menores valores de CE observado entre os tratamentos aos 90 dias de incubação, porém apresentou os maiores valores de CE em quase todo o período anterior, indicando a ocorrência de reações diferenciadas devido à maior dose da substância alcalina.

A adição de calcário não resultou em diferenças nos teores de $\mathrm{N}$ e na perda proporcional de $\mathrm{N}$ durante o processo de compostagem, além de não modificar as proporções de massa e volume iniciais. Por outro lado, os teores de $\mathrm{Ca}$ e Mg foram superiores nos compostos em que houve adição de calcário ao final da compostagem, o que já era esperado, devido ao fato de se tratar de um calcário dolomítico, responsável pelo aporte desses elementos.

De maneira geral, a adição de calcário no processo de compostagem da mistura de capim elefante com torta de mamona resultou em modificações nas propriedades do composto, sendo os efeitos expressos em maior intensidade pelo tratamento contendo a maior dose de calcário. Nesse sentido, recomenda-se a realização de mais trabalhos voltados para os efeitos do calcário, e de outras substâncias alcalinas, sobre o processo de compostagem, visando um maior entendimento sobre os estímulos positivos e reações desencadeadas sobre os compostos orgânicos. 


\section{REFERÊNCIAS}

ALVAREZ, V. H. V.; RIBEIRO, A. C.. Calagem. In: RIBEIRO, A. C.; GUIMARÃES, P. T. G.; ALVAREZ, V. H.. Recomendação para o uso de corretivos e fertilizantes em Minas Gerais: 5a Aproximação. 1999. p.43-60.

ARAÚJO, E. S.; MARSOLA, T.; MIYAZAWA, M.; SOARES, L. H. B.; URQUIAGA, S.; BODDEY, R. M.; ALVES, B. J. R.. Calibração de câmara semiaberta estática para quantificação de amônia volatilizada do solo. Pesquisa Agropecuária Brasileira, v.44, n.7, p.769-776, 2009.

AZEVEDO, D. M. P.; LIMA, E. F.. O Agronegócio da mamona no Brasil. Brasília: Embrapa Informação Tecnológica, 2001.

HECK, K.; MARCO, E. G.; HAHN, A. B. B.; KLUGE, M.; SPILKI, F. R.; SAND, S. T. V. D.. Temperatura de degradação de resíduos em processo de compostagem e qualidade microbiológica do composto final. Revista Brasileira de Engenharia Agrícola e Ambiental, v.17, n.1, p.54-59, 2013.

HUANG, D.; ZENG, G. M.; FENG, C. L.; HU, S.; ZHAO, M. H.; LAI, C.; W.; LIU, H. L.. Degradation of lead-contaminated lignocellulosic waste by Phanerochaete chrysosporium and the reduction of lead toxicity. Environmental Science and Technology, v.42, n.13, p.4946-4951, 2008.

INÁCIO, C. T.; MILLER, P. R. M.. Compostagem: ciência e prática para gestão de resíduos orgânicos. Rio de Janeiro: Embrapa Solos, 2009.

KÄMPF, A. N.. Produção comercial de plantas ornamentais. Guaíba: Agropecuária, 2000.

KIEHL, E. J.. Fertilizantes orgânicos. São Paulo: Agronômica Ceres, 1985.

LEAL, M. A. A.. Produção e eficiência agronômica de compostos obtidos com palhada de gramínea e leguminosa para o cultivo de hortaliças orgânicas. Tese (Doutorado em Agronomia, Ciência do Solo) - Universidade Federal do Rio de Janeiro, Rio de Janeiro, 2006.

LEAL, M. A. A.; GUERRA, J. M.; ESPINDOLA, J. A. A.; ARAÚJO, E. S.. Compostagem de misturas de capim-elefante e torta de mamona com diferentes relações C:N. Revista Brasileira de Engenharia Agrícola e Ambiental, v.17, n.11, p.11951200, 2013.

LIMA, J. T.. Obtenção de fertilizantes e substratos orgânicos a partir da compostagem de bagaço de cana mais torta de mamona e seu uso na produção de algumas hortaliças. Dissertação (Mestrado) - Universidade Federal do Rio de Janeiro, Rio de Janeiro, 2014.

MAGALHÃES, M. A.; MATOS, A. T.; DENÍCULI, W.; TINOCO, I. F. F.. Compostagem de bagaço de cana-de-açúcar triturado utilizado como material filtrante de águas residuárias da suinocultura. Revista Brasileira de Engenharia Agrícola e Ambiental, Campina Grande, v.10, n.2, p.466-471, 2006.

MELO, L. C. A.; SILVA, C. A.; DIAS, B. O.. Caracterização da matriz orgânica de resíduos de origens diversificadas. Revista Brasileira de Ciência do Solo, v.32, n.1, p.101-110, 2008.

OLIVEIRA, E. A. G.; LEAL, M. A. A.; ROCHA, M. S.; GUERRA, J. G. M.; RIBEIRO, R. L. D.. Avaliação da estabilidade de materiais orgânicos por meio de incubação e da captura conjunta das emissões de $\mathrm{CO}_{2}$ e de $\mathbf{N H}_{3}$. Seropédica: Embrapa Agrobiologia, 2014.

PEREIRA, A. V.; FERREIRA, R. P.; PASSOS, L. P.; FREITAS, V. P.; VERNEQUE, R. S.; BARRA, R. B.; SILVA, C. H. P. E.. Variação da qualidade de folhas em cultivares de capim-elefante (Pennisetum purpureum) e híbridos de capim-elefante $x$ milheto ( $P$. purpureum $\times P$. glaucum), em função da idade da planta. Ciência e Agrotecnologia, v.24, p.490-499, 2000.

PROCHNOW, L. I.; CUNHA, C. F.; KIEHL, J. C.. Controle da volatilização de amônia em compostagem, mediante adição de gesso agrícola e superfosfatos com diferentes níveis de acidez residual. Revista Brasileira de Ciência do Solo, v.25, n.1, p.65-70, 2001.

SILVA, F. C.. Manual de análises químicas de solos, plantas e fertilizantes. 2 ed. Brasília: Embrapa Comunicação para Transferência de Tecnologia, 2009.

A CBPC - Companhia Brasileira de Produção Científica (CNPJ: 11.221.422/0001-03) detém os direitos materiais desta publicação. Os direitos referem-se à publicação do trabalho em qualquer parte do mundo, incluindo os direitos às renovações, expansões e disseminações da contribuição, bem como outros direitos subsidiários. Todos os trabalhos publicados eletronicamente poderão posteriormente ser publicados em coletâneas impressas sob coordenação da Sustenere Publishing, da Companhia Brasileira de Produção Científica e seus parceiros autorizados. Os (as) autores (as) preservam os direitos autorais, mas não têm permissão para a publicação da contribuição em outro meio, impresso ou digital, em português ou em tradução. 